\title{
Lip Pit without a Pit - A Case Report
}

\author{
Khurshid A Mattoo* \\ Department of Prosthodontics, College of dentistry, Jazan University, Jazan, (KSA)
}

*Corresponding author: Khurshid A Mattoo, Department of Prosthodontics, College of dentistry, Jazan University, Jazan, KSA.

Received Date: December 16, 2019

Published Date: January 13, 2020

\begin{abstract}
Pitting of the lips is a is a sign of a developmental disorder which may or may not be associated with other systemic abnormalities. Lip pits are mostly associated with either cardiovascular or cerebral systemic disorders. The case present in this clinical report is unique since it presents a case of lip pit that failed to develop although its physical evidence was present. The patient was a young adult who was seeking dental treatment for an endodontically treated tooth, which was successfully accomplished with a porcelain fused to metal single crown.
\end{abstract}

Keywords: Hereditary; Commissure; Vander woudes syndrome; Chromosome

\section{Introduction}

Pitting of the lips is a congenital anomaly that follows the hereditary pattern (autosomal dominant), Everett FG and Wescott WB [1] is usually bilateral, and often symmetrical and occurs on the vermilion border of the lips or in the mucocutaneous line of the lips [2]. Based on location they can be either median upper, median lower and commissural lip pits [3]. Median lip pits are most common among the three types. When observed with the naked eye, the surface of the lip pit presents as a circular or a transverse slit which commonly have sinus tracts extending into the fibers of orbicularis oris muscle [2]. Significance of the presence of sinus tract is its reported incidence $(0.001 \%) 2$ in population and about $75 \%$ of the cases are associated with cleft lip and palate. The occurrence of lip pits is either isolated or associated with other developmental disturbances like popliteal pterygium syndrome, Van der Woude syndrome, oral-facial-digital syndrome and Marves and Cremer's (cleft tongue) syndrome [4-7].

Since other systemic abnormalities are present in syndromes associated with lip pits, both medical and dental clinicians should be aware of the underlying systemic associations since they influence treatment plans in such cases. We present a case of a young adult who presented with an obvious esthetic deformity of the mandibular lip in the form of incomplete lip pit formation.

\section{Case Report}

A young male adult aged 16 years reported to the department of prosthodontics for restoration of endodontically treated mandibular right first molar. The patient had developed an abscess in relation to the same tooth for which he was treated in the department of Endodontics [6] weeks back. The patient's medical history was noncontributory to the current treatment plan. All vital signs were within normal limits. Questions that would indicate a cardiovascular or cerebral disorder were negatively reported by the patient.

General body examination revealed no abnormalities of the hands, feet, chest or other skeletal components. Extra oral examination showed pale brownish complexion with multiple moles on the facial skin (Figure 1). Maxillary lip appeared long while the most prominent feature of the face was a bilateral disruption of lip contour that corresponded to the walls that form the maxillary philtrum. The surface of the mucosa over these bilateral areas was smooth while creating a trough in between them, in which the tubercle of the maxillary lip would lie when the lips were closed at rest position of the mandible (Figure 1). Closer examination of the mandibular lips revealed two deep pits within the everted areas. However, palpation of the areas with a probe did not show any evidence of a break in the mucosa suggesting absence of pits. Intra oral examination did not show any developmental disturbance of the teeth, alveolar bone or temperomandibular joint. The arch of the maxillary palate was normal with normal clinical features of maxillary tuberosity and retromolar pad.

Radiographic investigation of the cranium demonstrated a mild bimaxillary protrusion without any evidence of absence of 
teeth (Figure 2). Dental examination revealed an endodontically treated mandibular right first molar with the gross destruction of the crown. Treatment plan presented and consented by the patient was the fabrication of a single crown on a silver amalgam core build up that was retained by the cavity design. A porcelain fused to metal single crown with buccal facing was done for the patient using routine fixed partial denture procedures.
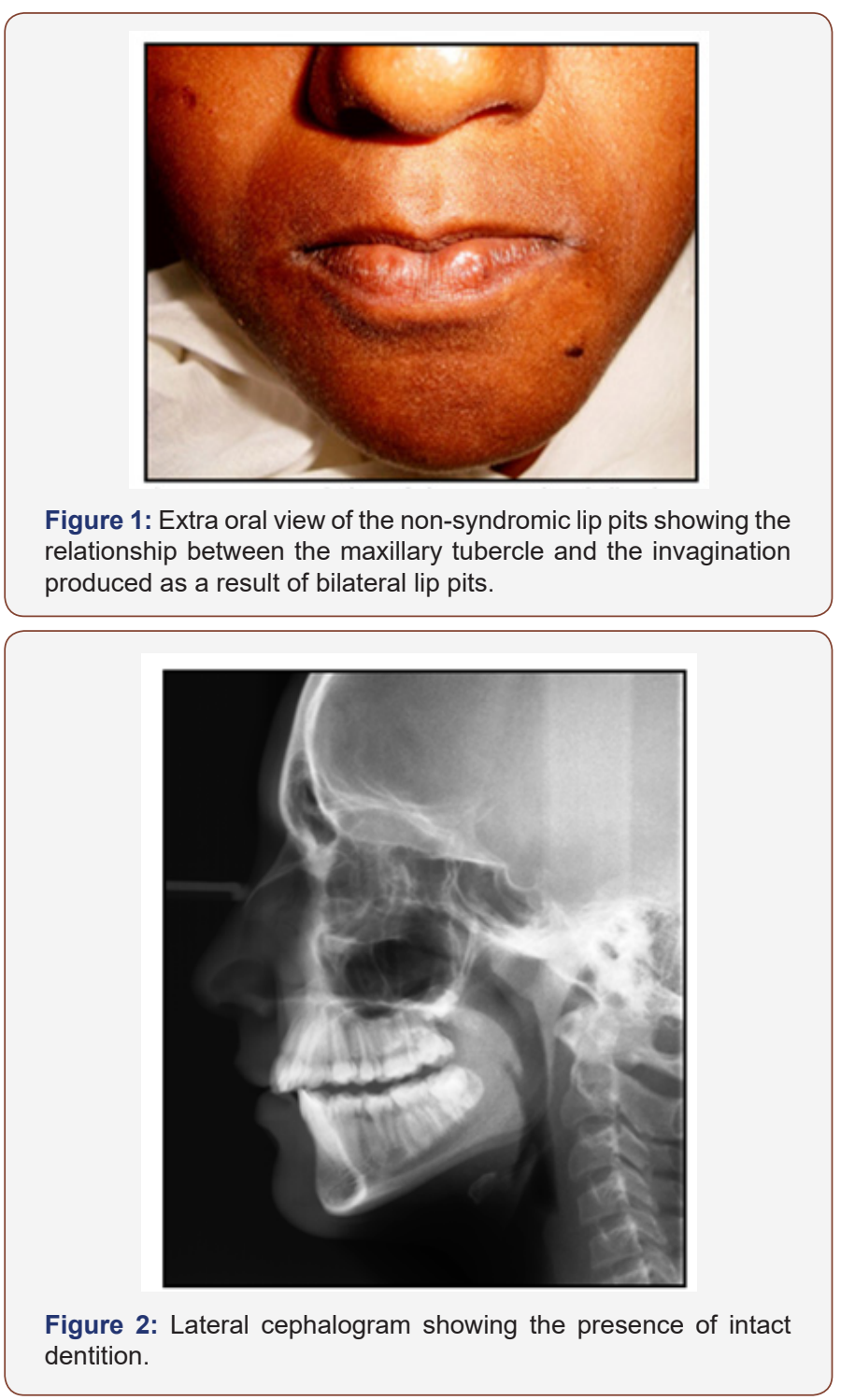

\section{Discussion}

We present a case (Figure 1) of bilateral lip pits not associated with any syndrome and without having a pit, sinus or fistula. The clinical picture of pits has mistakenly been considered as though indentations made by maxillary incisors. Coincidentally, the first case reported by Demarquay in 1845 was also thought to be due to indentations. Today, however with genetic advances, the lip pits have been established to occur due to IRF6 (interferon regulatory factor) mutations.

Lip pits result due to notching of lip thus fixing the tissues at the base of the notch at the same time or due to failure of union of embryonic lateral sulci of the lip. Sporadic lip pits not associated with other developmental disturbances are rare, which is why there is no recorded prevalence of isolated lip pits in the literature [8]. Lip pits pose a cosmetic problem for the person with resultant psychological consequences who has it since the pitting is present on the lips and alter the contour of the lips as in this case. In some cases, accessory salivary glands usually drain into these blind tracts of fistulas associated with pits, due to which saliva exudes from the pit. The present case demonstrates that a tract or a fistula is not necessarily present with lip pit, therefore forceful palpation with probes should be avoided. The median lip pit must be differentiated from the commissural lip pit, which are seen at the commissures of the mouth.

Since the condition of lip pit has been associated with various syndromes which mainly affect cerebral and cardiovascular besides creating skeletal deformity, it is imperative to rule out any such abnormality. Polythelia is the presence of a supernumerary nipple, which has been associated with lip pits [9]. History and general examination should focus on eliciting any sign or symptom associated with cerebral, cardiovascular and skeletal system. Oral manifestations may include hypodontia, oligodontia, narrow arched hard palate, adhesions between gum pads (at birth), orofacial clefts or cleft lip and palate. Careful palpation of the commissures should be done to rule out existence of commissural pits. Non evident cleft palate demands palpation of the hard palate to rule out the existence of a submucous cleft palate. To rule out other syndromes one must also investigate reproductive organs (genitals), appendages like skin and nails, syndactyly of finger digits and toes.

Lip pits when causing esthetic embarrassment may be removed surgically while taking care to remove the entire lip pit canal if present. Leaving remnants of ducts can lead to the development of mucoid cysts in the future.

\section{Conclusion}

Although lip pits are innocuous, clinicians must investigate cardiovascular and cerebral systems when they encounter such cases. Impairment on facial esthetics is of serious concern when cleft lip or cleft palate is associated.

\section{Acknowledgement}

None.

\section{Conflict of Interest}

No conflict $\mathrm{f}$ interest.

\section{Refernces}

1. Everett FG, Wescott WB (1961) Commissural lip pits. Oral Surg 14(2): 202-209.

2. Ravi Prakash SM, Verma S, Singh U, Agarwal N (2013) Congenital lip pits: Report of cases with variable expressivity. E J Dent 3: 453-456.

3. Baker BR (1966) Pits of the lip commissures in Caucasoid males. Oral Surg 21(1): 56-60.

4. Premakumar P, Thomas J, Rani P, Vineet D, Thomas S, et al. (2013) Prevalence of commissural lip pits in patients visiting a dental college in a rural area of South Kerala: A Pilot study. IOSR J Dent Med Sci 10: 59-61.

5. Spencer L, Gondim D, Alves R, Silva C, Lopes V (2012) Popliteal pterygium syndrome: Case report and literature review. Rev Bras Cir Plást 27: 482486. 
6. More CB, Varma S, Tailor M, Bhavsar K (2013) Van der Woude syndrome: Report of two cases with supplementary findings. Indian J Dent Res 24(3): 387-389.

7. Marres HA, Cremers CW (1991) Congenital conductive or mixed deafness, preauricular sinus, external ear anomaly, and commissural lip pits: An autosomal dominant inherited syndrome. Ann Otol Rhinol Laryngol 100(11): 928-32.
8. Manoharan GVMG, Singh K, Reghu P (2013) Congenital lower lip pits Report of a rare case. Int J Dent Case Rep 3: 146-150.

9. Rizos M, Soyropoulos MN (2004) Van der woude syndrome: a review. Cardinal signs, epidemiology, associated features, differential diagnosis, expressivity, genetic counselling and treatment. Eur J Orthod 26(1):1724. 